\title{
A organização eclesiástica da Comunidade Cristã Nova Esperança: entre acolhimentos e o desacolhimentos
}

\author{
The ecclesiastical organization of The Christian Community Nova Esperança: \\ between welcoming and exclusion.
}

\author{
Rubio José Ferreira* \\ Moizes Generino da Silva**
}

\begin{abstract}
Resumo
As igrejas inclusivas nascem da necessidade de um grupo minoritário e excluído das igrejas convencionais ter seu espaço para praticar a sua religiosidade de forma livre e aceita independente da sua orientação sexual. Assim, cabe indagar quais são os modelos de estruturação institucional que são construídos nas igrejas inclusivas, e em que medida essas estruturas eclesiásticas são capazes de propiciar que elas cumpram sua 'missão' de 'acolher' pessoas gays, lésbicas, travestis e transexuais. A pesquisa que embasa o trabalho foi desenvolvida por meio de revisão bibliográfica, visitas aos cultos da Comunidade Cristã Nova Esperança e realização de entrevistas com líderes e frequentadores dessa Igreja, no sentido de realizar os objetivos propostos na pesquisa. A estrutura organizacional da CCNE assemelha-se ao modelo da igreja tradicional, o que, em certa medida, dificulta o acolhimento aos seus frequentadores.
\end{abstract}

Palavras-chave: Igrejas Inclusivas. Organização Eclesiástica. Evangélicos.

\begin{abstract}
Inclusive churches arise from the need of minority and excluded groups from conventional churches to practice their religiosity in a free manner that accepts their sexuality. Thus, we need to ask what the models of institutional structuration in these inclusive churches are, and also the extent to which the ecclesiastical structures can propitiate the 'mission' of 'welcoming' gays, lesbians, transvestite and transsexuals. The research was carried out through a literature review, visiting the services of Comunidade Cristã Nova Esperança (CCNE or "New Hope Christian Community"), and interviews with church leaders and members of this Church. The organizational structure of CCNE is quite similar to the traditional church which, to some extent, makes the welcoming of church members difficult.
\end{abstract}

Keywords: Inclusive churches, ecclesiastical organization, evangelicals.

Comunicação recebida em 15 de maio de 2015 e aprovada em 24 de dezembro de 2015.

* Doutor em Geografia (2013) pela UFPE, professor da Universidade Federal do Oeste da Bahia - UFOB. País de origem: Brasil. E-mail: rubio.ferreira@pq.cnpq.br

** Especialista em Psicopedagogia e Ciências da Religião (UCAM), Educação de Jovens e Adultos-EJA (UNIANDRADE), professor do Ensino Fundamental I e II e Médio. País de origem: Brasil. E-mail: professormoizesgenerino@hotmail.com 


\section{Introdução}

Partindo do pressuposto de que a organização eclesiástica interfere positiva e, às vezes, negativamente no processo de acolhimento também nas igrejas inclusivas, o presente ensaio busca analisar em que medida a organização eclesiástica da Comunidade Cristã Nova Esperança (CCNE) possibilita que seus fiéis e frequentadores experimentem efetivo acolhimento. Essa Igreja procura acolher um público marginalizado no que tange à vivência da religiosidade cristã no contexto evangélico pentecostal e neopentecostal.

Os participantes dessa Comunidade comumente empregam em sua igreja atual modelos das igrejas de origem, no que tange aos rituais e símbolos. A pergunta de partida pode ser formulada nos seguintes termos: qual a diferença do governo eclesiástico da $\mathrm{CCNE}$ em relação às igrejas evangélicas pentecostais tradicionais? Sendo uma igreja que se alinha a uma perspectiva minoritária, é relevante conhecer suas formas de organização e administração. Assim, cabe indagar quais modelos de estruturação institucional são construídos em sua 'missão' de 'acolher' pessoas gays, lésbicas, travestis e transexuais. O discurso propagado concebe as práticas e identidades homossexuais não como 'pecado', mas como uma expressão da sexualidade humana legítima e benigna tanto quanto a heterossexualidade (NATIVIDADE, 2010)ํ․

A homossexualidade é um termo moderno que se refere às vivências humanas existentes em diversos contextos sociais. A ela são atribuídos diferentes significados, classificações e valores, no intuindo de defini-la e apresentá-la em ordens e espaços de saber e poder (FOUCAULT, 1985). Mesmo antes de existir essa nomenclatura, a religião já repudiava as pessoas que tinham relações afetivas e sexuais com pessoas do mesmo sexo. Usando argumentos bíblicos, líderes

\footnotetext{
${ }^{1}$ Agradecemos ao professor Dr. Marcelo Tavares Natividade pelo apoio na estruturação da pesquisa e pelas considerações insofismáveis para as reflexões ora apresentadas.
}

Horizonte, Belo Horizonte, v. 13, n. 40, p. 2292-2307, out./dez. 2015 - ISSN 2175-5841 
religiosos excluíam tais pessoas das igrejas. $\mathrm{Na}$ contemporaneidade, o contexto religioso brasileiro vem se tornando cada vez mais heterogêneo e complexo, entre os quais se destaca o advento das igrejas inclusivas, conforme sugere Natividade (2008).

De forma geral, o termo "igreja inclusiva" é utilizado para definir as igrejas cristãs que compartilham da ideia de que a sexualidade não precisa ser necessariamente heterossexual no que tange à religiosidade como nas igrejas tradicionais (ALVES, 2009). Isso significa dizer que a igreja inclusiva é baseada numa teologia que defende a heterogeneidade da sexualidade humana. Essas igrejas são recentes no Brasil. Nos anos de 1990, movimentos gays já haviam fomentado discussões sobre a exclusão dos homossexuais das igrejas cristãs e promovido a construção de grupos religiosos voltados às/aos LGBT. Uma das instituições precursoras deste movimento no país foi a Igreja Presbiteriana Unida de Copacabana, no Rio de Janeiro que, ao se posicionar publicamente a favor da inclusão das pessoas homossexuais nos cultos cristãos, chamou a atenção da mídia. A partir de então, a referida Instituição atraiu um grande número de fiéis homossexuais, fazendo com que passasse a ser conhecida como uma "igreja gay" (NATIVIDADE, 2010).

A pesquisa que embasa este ensaio foi desenvolvida por meio de revisão bibliográfica, que consiste em levantamento da bibliografia pertinente ao tema geral do trabalho. Para a realização desta etapa da pesquisa, foram feitas leituras de livros, teses, dissertações e artigos científicos que abordam temas como: igrejas inclusivas, evangélicos e a homossexualidade, igrejas pentecostais e neopentecostais, dentre outros. Também foram realizadas visitas aos cultos da CCNE, por vezes recorrendo à metodologia do trabalho de campo etnográfico, e por vezes recorrendo à metodologia de trabalho qualitativo, a partir da realização de entrevistas com os seguintes perfis de grupos de fiéis: i) pastores(as) e líderes de ministérios; ii) fiéis que se declaram membros da igreja, participantes de ministérios, mas que não desenvolvem função de liderança; e iii) frequentadores esporádicos. O objetivo foi o de compreender as dinâmicas de organização e 
estruturação dessa denominação e suas comunidades, as liturgias empregadas, bem como o "olhar" dos grupos dos fiéis em relação à CCNE.

As igrejas inclusivas são um indicador de que os valores cristãos são praticados atualmente com flexibilidade, ao ponto destas incorporarem a defesa da diversidade sexual e de gênero no âmbito religioso. Por outro lado, os participantes das igrejas inclusivas, em sua maioria, vêm das correntes tradicionais do pentecostalismo e do neopentecostalismo. Com efeito, os rituais das igrejas inclusivas são híbridos de elementos litúrgicos pentecostais e neopentecostais, consistindo essa a marca da construção da identidade de algumas igrejas inclusivas, até mesmo no que diz respeito a sua organização eclesiástica. O que se percebe é que igrejas inclusivas, cujo ethos religioso é predominantemente pentecostal, podem construir formas de organização semelhantes às das igrejas pentecostais tradicionais, por exemplo, recorrendo à figura do pastor presidente na centralização do poder.

\section{Igrejas Evangélicas, pentecostalismo e homoafetividade}

Pode-se destacar que o campo evangélico é constituído por distintas tendências em termos de doutrinas e rituais. Enquanto denominações históricas possuem cultos mais litúrgicos, centrados na leitura da Bíblia, denominações pentecostais e neopentecostais são fortemente marcadas pelo carisma, em cultos emocionais que evidenciam a crença nos dons do Espírito Santo e na influência do demônio na vida cotidiana. As ideias de "cura espiritual" e "libertação" assinalam a existência de performances rituais segundo as quais o diabo é derrotado pelo Poder de Deus. Nesse contexto, a homossexualidade é vista como possessão do diabo, e os indivíduos são submetidos a rituais de purificação e libertação. 
Na América Latina, o termo "evangélico" é usado para designar o grupo formado pelas igrejas protestantes históricas, pentecostais e neopentecostais. De acordo com Mariano (2004), o pentecostalismo se distingue do protestantismo histórico por acreditar na contemporaneidade dos dons do Espírito Santo, com ênfase nos dons de línguas e cura, e por sustentar a crença em preceitos e práticas do cristianismo primitivo, tais como a expulsão de demônios e a realização de milagres.

No Brasil, segundo dados do Instituto Brasileiro de Geografia e Estatística (IBGE), o número de evangélicos vem aumentando significativamente nas últimas décadas. Se em 2000 constavam de 26,2 milhões, ou 15,4\% da população brasileira, em 2010 os evangélicos somam 42,3 milhões de fiéis ou 22,2\% da população. Esse crescimento pode destacar uma influência marcante do pentecostalismo, movimento dentro do protestantismo, que ganhou notoriedade nas primeiras décadas do século XX e que hoje representa 13,3\% da população evangélica do país. Para Freston (1994), o pentecostalismo apresenta três momentos, aos quais ele chama de ondas, quais sejam: na primeira onda, vê-se o surgimento do pentecostalismo clássico ou histórico com a fundação da Congregação Cristã do Brasil (1910) e da Assembleia de Deus (1911); a segunda onda ocorre com o surgimento de novas igrejas que, durante os anos de 1950 e 1960, caracterizam-se pela "cura divina" ou a compaixão. Três igrejas principais fazem parte desta onda: Igreja do Evangelho Quadrangular (1951), Igreja Pentecostal Brasil para Cristo (1955) e Igreja Pentecostal Deus é Amor (1962); a terceira onda, denominada neopentecostalismo, começa no final dos anos 1970 e caracteriza-se pelo teleevangelismo ou "igreja eletrônica", tendo sua representação marcante na Igreja Universal do Reino de Deus e na Igreja Internacional da Graça de Deus. Esta vertente protestante sempre apresentou distinções eclesiásticas e doutrinárias (MARIANO, 1999), mas embora cada vertente do pentecostalismo tenha suas particularidades e doutrinas, em todas elas há a interdição ao consumo de álcool, tabaco e drogas e ao sexo extraconjugal e homossexual (MARIANO, 2004). 
No cenário religioso brasileiro surgem, na última década do século $\mathrm{XX}$, as igrejas inclusivas, que se destacam por serem um fenômeno recente que chama atenção pela compatibilização de condutas não heterossexuais e cristianismo. Esse movimento, em certa medida, quebra o paradigma da determinação do lícito e ilícito tal qual apresentou Foucault (1985). Por outro lado, Fátima Jesus (2012) define que igreja inclusiva, além de um termo êmico, bastante controverso, pelo qual se designam as igrejas, pode em geral ser definido em termos de compatibilizar sexualidades não heterossexuais e religiosidades cristãs; tais igrejas não são discriminatórias às pessoas LGBT ou GLBTT.

As igrejas inclusivas nascem da necessidade de um grupo minoritário e excluído das igrejas convencionais ter seu espaço para cultuar, praticar a sua religiosidade de forma livre e aceita independente da sua orientação sexual. A expansão das igrejas inclusivas se dá não apenas pela experiência de exclusão de seus líderes nas suas igrejas de origem, mas, sobretudo pela configuração de importantes diferenças teológicas e de adoção de condutas morais (sexuais) entre as próprias igrejas inclusivas.

Segundo a análise de Rodrigues (2007), essas igrejas têm em comum o fato de que seus fundadores são oriundos de denominações cristãs tradicionais e que, em determinado momento de suas vidas, desligaram-se das mesmas. Em alguns casos, fica evidente a manutenção da estrutura organizacional da igreja nos moldes das denominações de origem das lideranças. Um exemplo disso é a CCNE, que nos cultos e na sua organização eclesiástica tem suas formas de administração institucional amparadas nos modelos da Assembleia de Deus, uma igreja pentecostal histórica. A CCNE, como uma comunidade inclusiva, possibilita experiências religiosas plurais que incluem o exercício da vida eclesial para pessoas LGBT, que - somente nessas igrejas - podem se tornar pastores e pastoras, presbíteros e presbíteras, diáconos e diaconisas, obreiros e obreiras. Isso é distinto das demais comunidades evangélicas, nas quais prevalece o interdito da ordenação de homossexuais (NATIVIDADE, 2010). Nas igrejas tradicionais, 
pessoas que ostentem publicamente uma identidade homossexual não podem exercer funções eclesiais. Esse, portanto, constitui-se de aspecto que favorece as igrejas inclusivas no sentido de atrair fiéis.

\section{A Estruturação Institucional da CCNE}

A CCNE foi fundada em 2004, em São Paulo (SP), por evangélicos oriundos da Igreja Acalanto, que divergiram teologicamente da sua liderança, formando uma nova igreja inclusiva. Atualmente, a CCNE conta com aproximadamente 2.800 membros distribuídos em congregações nos estados de São Paulo, Rio Grande do Norte, Pernambuco, Piauí e Ceará.

Segundo o pastor presidente da CCNE, “A igreja promove reuniões regulares de seus membros, à luz das Sagradas Escrituras; a divulgação do Evangelho de Jesus Cristo a toda e qualquer pessoa e em qualquer lugar (nacional e internacional); promove a integração à sociedade e à convivência cristã de todas as pessoas, principalmente daquelas que se encontram ao desabrigo da caridade humana, ou marginalizadas, ou enfermas, ou entregues a vícios e condutas antissociais, para que se cumpra o desejo manifestado por Jesus Cristo; promove a Paz, a Tolerância, o Respeito ao Próximo, o Amor ao Próximo, o Aperfeiçoamento do ser humano, o Respeito à Diversidade Humana, o Respeito à Vida Humana e a Confraternização Universal”.

No que tange à identidade da CCNE, especificamente no que diz respeito às crenças e práticas pentecostais ou neopentecostais, vale destacar que devido ao fato de seus membros serem advindos de diversas igrejas evangélicas, há diversidade também nos rituais dos cultos. No sentido de classificar a CCNE, Lima (2009, p. 34) destaca-a como uma igreja neopentecostal, visto que "as celebrações religiosas são cheias de louvores, danças e celebrações”. 
No que tocante à liturgia, a CCNE mantém as características de uma igreja evangélica convencional. Nos seus cultos emprega louvores, orações, pregação e convite aos visitantes não evangélicos. Uma vez convertidas, as pessoas cumprem os rituais do batismo nas águas e da celebração da Santa Ceia.

No tocante à estrutura organizacional, o Regimento Interno da CCNE adota o modelo episcopal para governo eclesiástico. Essa forma de governo é caracterizada por tomar a figura de um "Líder Maior" - geralmente chamado de Epíscopo, Papa, Bispo, Pastor Presidente ou Apóstolo -, que governa todos os outros líderes e demais membros da igreja. É ele quem toma todas as decisões. Ou seja, "um” governa a "todos". São exemplos desse modelo as igrejas Episcopal, Universal do Reino de Deus, Católica, Assembleia de Deus e a maioria das igrejas neopentecostais.

Segundo o Estatuto Social da CCNE, a Diretoria Executiva da Igreja é composta por seis membros: Presidente, Vice Presidente, Secretário, Vice Secretário, Tesoureiro e Vice Tesoureiro. Também é divida em três Conselhos Eclesiásticos: i) Conselho Eclesiástico Federativo (CEF), que exerce jurisdição sobre todos os demais conselhos eclesiásticos e espirituais da igreja e é composto exclusivamente pelo Conselho Eclesiástico da Igreja Sede e 05 (cinco) representantes do Conselho Eclesiástico Regional; ii) Conselho Eclesiástico Regional (CER), que exerce jurisdição sobre dois ou mais Conselhos Eclesiásticos estaduais; e iii) Conselho Eclesiástico Local (CEL), que exerce jurisdição sobre a igreja local.

Considerando a organização eclesiástica da CCNE, faz-se necessário atentar, também, para uma análise do carisma² dos seus líderes. Até porque, a forma como o(s) líder(es) de uma igreja conduz(em) seus liderados repercute diretamente na satisfação, ou não, dos liderados. Sobre isso, Fátima Jesus (2012) destaca que as

\footnotetext{
${ }^{2}$ Carisma é uma qualidade pessoal considerada extracotidiana e em virtude da qual se atribuem a uma pessoa poderes ou qualidades sobrenaturais, sobre-humanos ou, pelo menos, extracotidianos específicos, ou então se a toma como pessoa enviada por Deus, como exemplar e, portanto, como "líder". (WEBER, 2000, p. 158, 159).
} 
experiências do pastor presidente em uma igreja tradicional influenciam diretamente no seu governo eclesiástico. Ao mesmo tempo, Araújo (2007) salienta que a estrutura e o sistema de comando entre as denominações pentecostais, em geral, seguem as estruturas congregacionais, presbiterianas e episcopais. Destarte, vale ressaltar que as igrejas neopentecostais se estruturam de maneira informal ou paraclesiásticas, sob a liderança de personalidades dominantes, em geral, seus fundadores.

No caso das igrejas pentecostais e neopentecostais, o carisma do(s) líder(es) se sobressai mais claramente no sentido de influenciar o comportamento dos membros. Sobre isso, Meyer (2007) afirma que a maioria dos líderes usa sua influência para persuadir seus liderados e se utiliza da autocracia para manter-se no poder sem a participação do grupo nas decisões.

Ao que parece, a CCNE, ao definir a sua organização eclesiástica baseada no modelo episcopal, ao mesmo tempo em que concentra o governo na figura do líder maior, promove alguma descentralização do governo quando se apropria da organização por diretorias, conselhos etc. Contudo, considerando que a figura do líder maior exerce poder sobre os demais líderes, algumas fragilidades são evidenciadas, especialmente no que tange à falibilidade humana.

Desta feita, faz-se necessário buscar refletir em que medida a estruturação do poder, ou, em outras palavras, a organização administrativa da CCNE, bem como as posturas dos seus líderes diante de questões que ultrapassam a liturgia de culto e o acolhimento inicial das pessoas GLBT, efetivamente contribuem para que os fiéis desta igreja encontrem nela lugar de efetivo acolhimento e não exclusão.

\section{Experiências de Acolhimento e de desacolhimento}

Analisando a organização eclesiástica da CCNE e a sua influência em termos de acolhimento, pode-se destacar que, se por um lado trata-se de uma igreja que 
incialmente abarca a todas as pessoas, independente de sua orientação sexual, por outro, é possível notar na forma como está constituída a sua estrutura organizativa (eclesiástica e administrativa) a ocorrência de fragilidades no que tange à permanência de boa parte do seu público. Isso é evidente quando se identificam movimentos de insatisfação por parte dos membros e fiéis na CCNE. Parte dessas insatisfações diz respeito à forma como alguns dos líderes dessa Igreja se portam cotidianamente perante os membros e fiéis, ou seja, como conduzem o andamento da igreja.

Quando se trata da escala de atuação dos líderes e, por sua vez, do convívio cotidiano na igreja, observa-se que ao mencionar os líderes nacionais ou regionais, quer seja pastores ou conselheiros, líderes de ministérios e/ou departamentos, a maior a parte dos fiéis aponta que se tratam de pessoas "consagradas"; portanto, dotadas de dons espirituais que são destinados ao bom funcionamento da igreja. Por outro lado, quando se referem aos líderes locais, os quais estão presente cotidianamente nos cultos, as opiniões dos frequentadores e membros divergem um pouco dos juízos feitos aos líderes nacionais e regionais.

Ao que se percebe, há divergências quanto ao "olhar" dos fiéis acerca dos líderes. Essas divergências muitas vezes são mais claras quando há convivência mais próxima e não se concorda com as posturas dos líderes. Claro que as divergências existem em qualquer grupo social, especialmente quando a relação entre líderes e liderados é cotidiana. Não se pretende aqui ajuizar as atitudes dos pastores, contudo, não se pode deixar de observar que o líder de uma comunidade precisa apresentar habilidades de influência positiva sobre os liderados. Caso contrário, as fragilidades do líder ficam em evidência, o que poderá constituir, também, fragilidade da igreja no que tange ao acolhimento.

Especificamente acerca do acolhimento, os fiéis foram perguntados com se sentem na igreja, se pretendem continuar frequentando a CCNE, se já tiveram experiências em outras igrejas inclusivas. As respostas são bem variadas em alguns 
aspectos, mas bem homogêneas em outros. Sobre o motivo de vir à CCNE, salvo poucos casos, a grande maioria buscava uma igreja para cultuar sem ter que tratar da sua homossexualidade; e ao tomarem conhecimento da igreja inclusiva, visitaram e frequentam regularmente. Sobre a pretensão de continuar frequentando a CCNE, a maior parte dos frequentadores mais recentes manifestou interesse em permanecer. Dos fiéis mais antigos, até entre os que assumem funções de liderança (como líderes de ministérios), pode-se detectar anseios em migrar ou fundar outras igrejas, também inclusivas.

Os entrevistados que sinalizaram intenção de migrar para outras igrejas foram indagados acerca dos motivos. Detectou-se que nos respondentes mais antigos na CCNE e que desempenham ou desempenharam alguma função de liderança nessa Comunidade ou em suas igrejas de origem, as respostas mais comuns dão conta que "o chamado de Deus" é imperioso, e que procurarão, ou organizarão, outras igrejas, para desenvolver seus dons.

Vale salientar ainda que as regras para a escolha das pessoas para exercerem funções de liderança na CCNE não são claras, já que não estão postas no seu Estatuto Social. Isso se constitui de uma fragilidade no que tange à organização eclesiástica da Igreja e, por sua vez, pode constituir fragilidade ao acolhimento. Até porque podem ser aguçados o individualismo e a competição no sentido da busca por funções de liderança na Igreja.

Outro aspecto da estrutura organizacional da CCNE que tem rebatimentos diretos no acolhimento de pessoas diz respeito às regras de conduta social. Se por um lado a ausência de regras claras da conduta social desejada aos fiéis dessa igreja constitui-se de atrativo às pessoas insatisfeitas com as regras de suas igrejas de origem, com o passar do tempo e com o cotidiano na CCNE, pode significar indícios para o desacolhimento. A maior parte dos fiéis antigos entrevistados apontou que presenciou ou foi alvo de situações em que as lideranças da igreja exigiram postura social baseada em regras da fé cristã, mas que as regras não haviam sido explicitadas anteriormente. 
Os aspectos mais citados pelos entrevistados, no que tange às regras de conduta social e de práticas religiosas, dizem respeito aos relacionamentos afetivos e aos costumes de convivência social. Informaram que não é claro se os fiéis podem consumir cigarros e bebidas alcoólicas; frequentar boates e bares; ter relações sexuais com pessoas com as quais não possuem vínculos afetivos ou relacionamentos consolidados etc., sem, com isso, "pecar" contra as regras da igreja.

Sobre esse aspecto, é possível detectar nos sermões e nas conversas com os líderes (pastores/as e líderes de ministérios) que as regras são as mesmas das igrejas tradicionais, as quais são baseadas na fé cristã. E que aos líderes é necessário que mantenham ilibada postura moral e espiritual, abstendo-se de bebidas alcoólicas, cigarros, "festas mundanas", promiscuidade sexual etc. Sobre isso, falou um líder de ministério: "Quando fui libertado das garras de Satanás, deixei lá fora todos os vícios ${ }^{3}$. Deus exige do crente gay a mesma coisa que exige dos crentes héteros.". Um pastor falou: "Oramos muito para que os crentes daqui encontrem um amor, e assim firmem compromisso. Há tantos dons desperdiçados porque os crentes não têm relacionamentos. Isso interfere na vida espiritual. Quando comungamos com a carne de quem não tem Jesus, abrimos a nossa vida para que a outra pessoa traga tudo de ruim para nós na vida espiritual. Não tem como a pessoa desenvolver os dons na igreja, ser usado por Deus para curar, profetizar e depois ir para uma boate e ter relações sexuais com qualquer pessoa”.

Ainda sobre regras de conduta social e espiritual na CCNE, vale destacar que os fiéis demonstram algum desconforto. Alguns egressos dessa igreja que também foram entrevistados informaram que as exigências para condutas social e religiosa são destinadas apenas a alguns dos fiéis, e a outros a exigência é mais branda. Sobre isso, falou um entrevistado: "Frequentei a CCNE durante um ano. Na minha convivência lá percebi que algumas pessoas faziam tudo que qualquer pessoa não

\footnotetext{
${ }^{3}$ Embora a questão dos vícios e das condutas antissociais conste no Estatuto Social da CCNE, esse estatuto não é amplamente divulgado nos cultos e celebrações. Portanto, não é de conhecimento de todos os frequentadores e membros.
} 
evangélica faz: bebe, fuma, não tem namorado sério etc. e ninguém da liderança pergunta nada. Pelo contrário, até defendem. Para outros, os líderes são rígidos, querem saber de tudo, o que a gente faz, para onde vai, com quem vai. Acho isso chato, porque são dois pesos e duas medidas”.

Ao que parece, as inconsistências no que tange à organização institucional da CCNE podem indicar fragilidades na missão de acolher pessoas. Se por um lado há o acolhimento inicial, baseado na possibilidade da prática religiosa considerando o princípio de que "Deus aceita a todos sem discriminação", por outro, a diferenciação no trato com os fiéis por parte dos líderes, em certa medida repercute em evasão ou acolhimento deficiente. Portanto, há que se questionar a efetividade do acolhimento pregado por essa igreja.

\section{À Guisa de Conclusão: qual acolhimento e qual desacolhimento?}

Apesar de o movimento inclusivo ser relativamente recente no Brasil, observa-se que ele congrega, em suas formas de organização, elementos das estruturas de igrejas tradicionais. Um dos pontos que deve ser destacado é a influência do ethos religioso das denominações de origem dos participantes. É na junção do novo e do tradicional que essas igrejas estão construindo suas identidades e conquistando legitimidade no campo religioso brasileiro ao propor discursos doutrinários que compatibilizam cristianismo e homossexualidade. Convém observar a rápida expansão dessas alternativas religiosas no Brasil, por meio de doutrinas, práticas, rituais e cosmologias que incorporam ao seu quadro de fiéis pessoas excluídas da sociedade e das demais igrejas tradicionais, como é o caso das pessoas LGBT. 
A organização eclesiástica da CCNE está fundamentada no mesmo paradigma de algumas igrejas evangélicas de poder centralizado. Apesar disso, há inovações em sua estrutura organizacional. Por exemplo, oferecem oportunidades para minorias sexuais, excluídas de suas igrejas de origem, para exercerem atividades eclesiais, independente de sua sexualidade divergente dos padrões dominantes da heterossexualidade. Contudo, vale destacar que esse "acolhimento" diz respeito à inclusão de pessoas GLBT no universo das práticas religiosas do campo das igrejas evangélicas, em oposição à exclusão clara para essas pessoas da maioria das igrejas evangélicas tradicionais.

No tocante ao acolhimento interno à CCNE, ou seja, na relação entre os líderes e os fiéis, que perpassa pela dimensão subjetiva da figura dos líderes, suas posturas diante dos fiéis, o poder de persuasão e carisma, etc., as inconsistências são evidentes. Isso significa que a organização eclesiástica per se dessa igreja não dá conta de contribuir para o efetivo acolhimento.

Claro que o presente ensaio não esgota o assunto, apenas o traz à tona no sentido de provocar o debate em torno da importância das igrejas inclusivas para o acolhimento de um público marginalizado, no que tange à vivência da religiosidade cristã de base pentencostal e neopentecostal. Outras pesquisas que contemplem comparações entre as organizações eclesiásticas de outras igrejas inclusivas, com vistas ao entendimento do efetivo acolhimento, que vão além da teologia inclusiva, são necessários. 


\section{REFERÊNCIAS}

ALVES, Zedequias. Religião e sexualidade: reflexões sobre igrejas inclusivas na cidade de São Paulo. 2009. Dissertação (Mestrado). Universidade Presbiteriana Mackenzie, São Paulo.

ARAÚJO, Isael. Dicionário do movimento pentecostal. Rio de Janeiro: CPAD, 2007.

FOUCAULT, Michel. História da sexualidade 1: a vontade de saber. Rio de Janeiro: Graal, 1985 .

FRESTON, P. Breve História do Pentecostalismo Brasileiro. In: ANTONIAZZI, et al. Nem anjos nem demônios: Interpretações sociológicas do pentecostalismo. Petrópolis:

Vozes, 1994.

INSTITUTO BRASILEIRO DE GEOGRAFIA E ESTATÍSTICA. Censo Demográfico 2010. Características gerais da população, religião e pessoas com deficiência. Rio de Janeiro: IBGE, 2012.

JESUS, Fátima Weiss. Unindo a cruz e o arco-íris: vivência, homossexualidades e trânsitos de gêneros na igreja da Comunidade Metropolitana de São Paulo. 2012. Tese (Doutorado), Universidade Federal Santa Catarina, Florianópolis.

LIMA, Bruno. Cristianismo e Homossexualidade: uma introdução à teologia inclusiva. Curitiba: Protexto, 2009.

MARIANO, Ricardo. Neopentecostais: sociologia do novo pentecostalismo no Brasil. São Paulo: Loyola, 1999.

MARIANO, Ricardo. Expansão pentecostal no Brasil: o caso da Igreja Universal. Estudos Avançados, São Paulo, v. 52, p. 121-138, 2004.

MEYER, Paul J. Os 5 Pilares da Liderança. São Paulo: Vida, 2007.

NATIVIDADE, Marcelo Tavares. Deus me aceita como eu sou? A disputa sobre o significado da homossexualidade entre evangélicos no Brasil. 2008. Tese de Doutorado em Antropologia- PPGSA/IFCS/UFRJ, Rio de Janeiro.

NATIVIDADE, Marcelo Tavares. Uma homossexualidade Santificada? Etnografia de uma comunidade inclusiva pentecostal. Religião e Sociedade, Rio de Janeiro, v. 30, n.2, p. 90-120, 2010, RODRIGUES, E. L. As Igrejas Inclusivas: movimento homossexual buscando seu espaço no meio evangélico. Apresentação Oral. Anais... XIV Encontro Nacional da ABRAPSO, São Paulo, 2007. 
WEBER, Max. Os tipos de dominação e Sociologia da Religião (tipos de relações comunitárias religiosas). In: WEBER, Max. Economia e Sociedade: Fundamentos da sociologia compreensível. Tradução de Regis Barbosa e Karen Elsabe Barbosa. Brasília: UnB, v. I, p. 139-198, 279-418, 2000. 